\title{
SURVEILLANCE DES AGENTS PATHOGÈNES D'ORIGINES VIRALE, BACTÉRIENNE ET PARASITAIRE CHEZ DES BOVINS IMPORTÉS AU GABON POUR LA CONSOMMATION : UNE ÉTUDE EN ABATTOIR
}

\author{
SURVEILLANCE OF VIRAL, BACTERIAL AND PARASITIC PATHOGENS IN \\ CATTLE IMPORTED IN GABON FOR CONSUMPTION: A SLAUGHTE- \\ RHOUSE STUDY
}

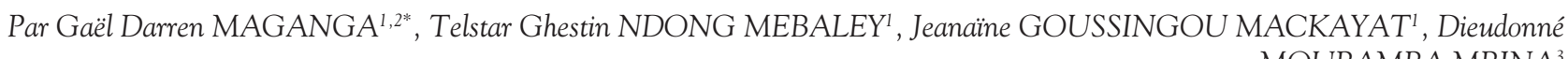
MOUBAMBA MBINA ${ }^{3}$

(Manuscrit reçu le 3 juillet 2021 et accepté le 4 octobre 2021)

\begin{abstract}
RÉSUMÉ
Le Gabon est un pays exclusivement importateur de bétail destiné à la consommation. L'introduction et les mouvements d'animaux sur le territoire ne font pas l'objet d'un contrôle rigoureux, l'exposant ainsi au risque d'introduction des maladies animales transfrontalières. L'objectif de cette étude est de rechercher et d'identifier les agents pathogènes d'origine virale, bactérienne et parasitaire chez des bovins importés et abattus au niveau du principal abattoir du pays, à Libreville. A partir d'organes et de sang prélevés post-mortem sur 125 zébus mâles, nous avons identifié des flavivirus de moustiques et un flavivirus génétiquement proche (plus de $97 \%$ d'identité nucléotidique) du virus du Nil occidental, chez un zébu Goudali. L'analyse phylogénétique révélait que cette souche virale groupait avec des souches de la lignée 2. Aussi, Babesia sp. a été identifiée chez 5 autres zébus Goudali. Des études et analyses complémentaires devraient être réalisées pour mieux caractériser les agents pathogènes hébergés par ces animaux.
\end{abstract}

Mots clés : abattoir, bovins, surveillance, maladies animales transfrontalières, Virus du Nil occidental, Babesia sp.

\begin{abstract}
- ABSTRACT
Gabon is a country that exclusively imports livestock for consumption. The introduction and movement of animals into the territory is not strictly controlled, exposing it to the risk of introducing transboundary animal diseases. The objective of this study is to research and identify pathogens of viral, bacterial and parasitic origin in imported cattle slaughtered at the country's main slaughterhouse in Libreville. From organs and blood collected post-mortem from 125 male zebus, we identified mosquito flaviviruses and a flavivirus genetically close (more than 97\% nucleotide identity) to West Nile virus in a Goudali zebu. Phylogenetic analysis revealed that this viral strain was grouped with strains of lineage 2. Also, Babesia sp. was identified in 5 other Goudali zebu. Further studies and analyses should be carried out to better characterize the pathogens hosted by these animals.

Key-words: slaughterhouse, cattle, survey, transboundary animal diseases, West Nile Virus, Babesia sp.
\end{abstract}

1- Unité Emergence des Maladies Virales, Centre Interdisciplinaire de Recherches Médicales de Franceville (CIRMF), BP 769 Franceville, Gabon.

Courriel : gael_maganga@yahoo.fr

2- Laboratoire de Production et Santé Animales, Institut National Supérieur d'Agronomie et de Biotechnologies (INSAB), Université des Sciences et Techniques de Masuku (USTM), BP 941 Franceville, Gabon.

3- Laboratoire de Zootechnie, Institut de Recherches Agronomiques et Forestières, BP 2246, Libreville, Gabon, courriel : ddm040@yahoo.fr 


\section{INTRODUCTION}

Selon la FAO, les maladies transfrontalières (Transboundary Animal Diseases) sont des maladies d'une importance significative pour l'économie, le commerce et/ou la sécurité alimentaire d'un ensemble de pays. Elles peuvent se propager facilement à d'autres pays et atteindre des proportions épizootiques. Elles sont à l'origine de taux élevés de morts et de malades chez les animaux et ont de graves répercussions socio-économiques, voire des effets sur la santé publique et constituent une menace constante pour les moyens d'existence des éleveurs. Ainsi, la mobilité animale contribue à la diffusion de maladies à transmission directe, comme la péripneumonie contagieuse bovine, la peste des petits ruminants ou la peste porcine africaine mais également de zoonoses. En effet, les maladies animales peuvent avoir un effet direct sur la santé humaine dans le cas de zoonoses. Dans les pays à faible revenu, les zoonoses représentaient $13 \%$ du fardeau des maladies infectieuses alors que dans les pays riches elles étaient responsables de moins de $1 \%$ du fardeau des maladies infectieuses (Grace et al. 2012, Grace et al. 2015). Les agents pathogènes zoonotiques peuvent avoir un impact considérable sur la santé publique tant en termes de morbidité que de productivité du bétail (Clinton et al. 2014).

Le Gabon est un pays exclusivement importateur de bétail. En effet, dans ce pays l'offre en produits carnés issus de la production locale se résume principalement à la viande bovine, porcine, de volaille et de lapin. Toutefois, cette offre reste dérisoire et donc la satisfaction des besoins en protéines animales repose sur les importations (MAEDRCDHM, 2003). Malheureusement, l'introduction et les mouvements d'animaux sur le territoire gabonais ne font pas toujours l'objet d'un contrôle rigoureux par les autorités compétentes, ce qui l'expose au risque d'introduction des maladies animales transfrontalières. De plus, malgré l'existence sur le plan institutionnel d'administrations et d'organismes nationaux et internationaux en charge de la sécurité alimentaire et nutritionnelle, les informations sur les maladies animales et les problèmes de sécurité sanitaire des aliments sont inexistantes ou peu disponibles (MAEPG, 2017). L'amélioration de la connaissance de la situation sanitaire devrait s'appuyer sur des réseaux de surveillance et de recherche afin de mieux apprécier les évolutions épidémiologiques, et de disposer d'outils de diagnostic et de contrôle plus efficaces (Lancelot et al. 2011). Dans cette perspective, les abattoirs peuvent être utilisés comme outils de veille sanitaire. Selon l'article 6.2.1 du code terrestre de l'OIE, l'inspection en abattoirs est un instrument privilégié dans la surveillance sanitaire animale et humaine (Vanelle, 2018).

Cette étude visait à rechercher et 'identifier les agents pathogènes d'origine virale, bactérienne et parasitaire chez des bovins importés et abattus au niveau du principal abattoir national de Libreville, au Gabon, et à éventuellement évaluer leur potentiel pathogène pour l'homme et les animaux domestiques.

\section{MATÉRIEL ET MÉTHODES}

\section{Site de l'étude}

Cette étude a été menée de septembre à novembre 2018, à l'abattoir national d'Owendo, situé dans la province de l'Estuaire, dans la commune d'Owendo, au sud de Libreville, au Gabon.

\section{Collecte des échantillons}

L'autorisation de collecter des échantillons de zébus à l'abattoir national d'Owendo a été agréé par le Directeur Général de l'Agence Gabonaise de Sécurité des Aliments (Note N²30/MAEPG/SG/DGAGASA/DSH). Les prélèvements de sang et d'organes divers (foie, rate, intestins, poumons, reins, nœuds lymphatiques) ont été réalisés au moment de l'inspection post mortem sous la supervision du vétérinaire à l'abattoir, et les échantillons conditionnés dans des cryotubes Nunc ${ }^{\circledR}$ (Thermo Fisher Scientific, États-Unis). Le sang a été prélevé sur chaque animal au moment de la saignée, soit $4 \mathrm{~mL}$ de sang total, dans des tubes EDTA et secs Vacuette ${ }^{\circledR}$ (Greiner Bio-One, États-Unis). Les plasmas et sérums obtenus, de même que les échantillons d'organes, ont été conservés à $-80^{\circ} \mathrm{C}$ jusqu'à leur utilisation.

\section{Criblage moléculaire des pathogènes}

\section{Extraction des acides nucléiques}

Les acides nucléiques (ADN et $\mathrm{ARN}$ ) ont été extraits à partir du plasma et de surnageant de broyat d'un mélange de foie/rate et de broyat d'intestins. Les broyages ont été réalisés à l'aide d'un automate (GenoGrinder 2000 Spex CertiPrep ${ }^{\mathrm{TM}}$, Thermo Fisher Scientific) à 1500 tours/min. pendant deux minutes. Les ADN totaux ont été extraits à l'aide du kit commercial QIAamp DNA Mini Kit (Qiagen, Allemagne), suivant les recommandations du fabricant. Les extractions d'ARN ont été réalisées sur un automate EZ1 Advanced XL (Qiagen, Allemagne) en utilisant le kit EZ1 RNA Tissue Mini Kit (Qiagen, Allemagne) suivant les recommandations du fabricant.

\section{Amplifications géniques par PCR}

Les acides nucléiques étaient testés à l'aide de différentes PCR pour la recherche des Flavivirus, Paramyxovirus, Coronavirus, Phlebovirus, et pour la recherche plus spécifique du virus de la Fièvre aphteuse (tableau 1). Aussi, la recherche était élargie aux bactéries pathogènes telles que Campylobacter, Salmonella, Shigella, aux souches d'Escherichia coli diarrhéiques (E. coli entéro-agrégatif, E. coli entéro-toxigène, E. coli entéro-pathogène, $E$. coli entéro-hémorragique et E. coli entéro-invasif). Pour ce faire, deux jeux de PCR multiplex, utilisant des amorces précédemment publiées (Kong et al. 2002 ; Vidal et al. 2004 ; Sjöling et al. 2007 ; Li et al. 2009 ; Rodas et al. 2011 ; Tobias \& Vutukuru, 2012 ; Sjöling et al. 2015), ont été utilisées. Par ailleurs, les bactéries Rickettsia sp. et Ehrlichia ruminantium ont également été recherchées à l'aide de deux PCR distinctes, précédemment publiées, basées respectivement sur l'amplification d'un fragment du gène ompA (Roux et al. 1996) et d'un fragment du gène pCS20 (Esemu et al. 2018). Enfin, les protozoaires sanguins Babesia sp. ont également été recherchés par PCR ciblant un fragment de 452 paires de bases ( $\mathrm{pb}$ ) du gène ARNr 18S, comme précédemment décrit par Casati (2005).

\section{Analyses des séquences et phylogénie}

Les produits de PCR de tailles attendues, après migration sur gel d'agarose de $2 \%$, ont été séquencés. Les séquences obtenues ont été analysées et les contigs assemblés à l'aide du logiciel bioinformatique ChromasPro version 1.5. Les séquences nucléotidiques 
étaient comparées à celles disponibles dans la base de données en ligne GenBank, en utilisant l'algorithme "Blastn" disponible dans NCBI BLAST (Basic Local Alignment Search Tool) (www.blast.ncbi.nlm.nih.gov) (Altschul \& Lipman, 1990). L'alignement des séquences a été réalisé en utilisant le programme d'alignement multiple des séquences, Clustal W, contenu dans MEGA X version 10.2.5 (Kumar et al. 2018). La phylogénie a été déduite en utilisant 1000 réplications de bootstraps à l'aide de la méthode du maximum de vraisemblance et le modèle Tamura-Nei (Tamura \& Nei, 1993). Une distribution Gamma discrète a été utilisée pour modéliser les différences de taux d'évolution entre les sites ( 5 catégories $(+\mathrm{G}$, paramètre $=5,8368))$. Cette analyse a porté sur 25 séquences nucléotidiques. Les analyses évolutives ont été réalisées dans MEGA X version 10.2.5.

Tableau 1 : Systèmes de PCR utilisés pour la recherche de virus ciblés

\begin{tabular}{|c|c|c|c|c|}
\hline $\begin{array}{l}\text { Agents } \\
\text { pathogènes }\end{array}$ & Noms amorces & PCR & Gène cible & Références \\
\hline $\begin{array}{l}\text { Virus } \\
\text { Coronavirus }\end{array}$ & $\begin{array}{l}P C 2 A S 1 \\
P C 2 S 2 \\
P C S \\
P C N A S\end{array}$ & RT-PCR nichée & $\begin{array}{l}\text { Polymérase } \\
\text { (L) }\end{array}$ & $\begin{array}{l}\text { De Souza Luna et } \\
\text { al. } 2007\end{array}$ \\
\hline Paramyxovirus & $\begin{array}{l}R M H F 1 \\
R M H F 2 \\
R M H R\end{array}$ & $\begin{array}{l}\text { RT-PCR semi- } \\
\text { nichée }\end{array}$ & $\begin{array}{l}\text { Polymérase } \\
\text { (L) }\end{array}$ & Tong et al. 2008 \\
\hline Phlebovirus & $\begin{array}{l}N \text {-phlebol } 1+ \\
N \text {-phlebol } 1- \\
N \text {-phlebol } 2+ \\
N \text {-phlebol } 2+\end{array}$ & RT-PCR nichée & $\begin{array}{l}\text { Polymérase } \\
\text { (L) }\end{array}$ & $\begin{array}{l}\text { Sanchez-Seco et } \\
\text { al. } 2003\end{array}$ \\
\hline Flavivirus & $\begin{array}{l}\text { PF } 1 S \\
\text { PF2Rbis } \\
\text { PF3S }\end{array}$ & $\begin{array}{l}\text { RT-PCR semi- } \\
\text { nichée }\end{array}$ & NS5 & $\begin{array}{l}\text { Crochu et al. } \\
2004 \text {; Cook et al. } \\
2006\end{array}$ \\
\hline $\begin{array}{l}\text { Virus de la } \\
\text { fièvre aphteuse } \\
\text { (Sérotype } 0 \text { ) }\end{array}$ & $\begin{array}{l}O-1 C 244 F \\
\text { EUR-2B52R }\end{array}$ & PCR & VP1 & Ayelet et al. 2009 \\
\hline $\begin{array}{l}\text { Virus de la } \\
\text { Fièvre de la } \\
\text { Vallée du Rift }\end{array}$ & $\begin{array}{l}R V S \\
R V A s \\
R V P\end{array}$ & PCR temps réel & $\mathrm{G} 2$ & $\begin{array}{l}\text { Drosten et al. } \\
2002\end{array}$ \\
\hline
\end{tabular}

\section{RÉSULTATS}

\section{Caractéristiques des animaux}

Au total, 125 bovins ont été prélevés et étudiés. Ces bovins de boucherie étaient présents à l'abattoir depuis moins de trois semaines. Ils provenaient du Tchad et du Cameroun. Il s'agissait de zébus mâles, âgés de 4 à 6 ans, incluant 112 apparte- nant à la race Goudali et 13 zébus de race Mbororo. Ces animaux n'ont pas subi d'examen clinique avant l'abattage.

\section{Les agents pathogènes détectés}

Dans cette étude, des virus appartenant au genre Flavivirus, ainsi que des hémoparasites du genre Babesia ont été identifiés. Cependant, aucun des bovins n'a été trouvé positif pour les autres virus et agents pathogènes recherchés. 
Détection et caractérisation des flavivirus

Les échantillons de foie et de rate des 125 bovins ont été analysés pour la recherche par PCR semi-nichée amplifiant un fragment de $210 \mathrm{pb}$ du gène de la polymérase des flavivirus. Des flavivirus ont été détectés chez 17 d'entre eux, soit un taux de positivité de 13,6\%. Parmi les 17 zébus, 15 appartenaient à la race Goudali et les 2 autres à la race Mbororo, soit des taux de d'infection respectifs de $13,39 \%(15 / 112)$ et $15,38 \%(2 / 13)$. Trois séquences nucléotidiques ont été obtenues. L'analyse par BLAST de ces séquences nucléotidiques a révélé d'une part que toutes les séquences correspondaient aux séquences de Flavivirus, et d'autre part que l'une de ces séquences était génétiquement très proche de séquences appartenant à différentes souches du virus du Nil occidental ou West Nile virus. Le bovin infecté par ce virus était un zébu de race Goudali (G40). Les deux autres séquences appartenaient à des flavivirus non pathogènes, isolés de moustiques du genre Culex. L'analyse phylogénétique, réalisée sur la base de séquences nucléotidiques partielles du gène de la polymérase du virus du Nil occidental, a montré que la souche virale détectée chez le zébu Goudali (G40) se groupait dans le même cluster génétique que des souches virales appartenant à lignée 2 (figure 1). Le pourcentage d'identité au niveau nucléotidique entre la souche gabonaise et les autres souches de la lignée 2 variait de $95 \%$ à $98 \%$. L'apparenté génétique la plus proche (98\%) était observée avec les souches LEIV-3266Ukr, identifiée chez un oiseau en Ukraine en 1960 (numéro d'accession GenBank JX041631), B956 provenant d'un humain en Ouganda en 1937 (AY532665) et ArD76104, isolée au Sénégal en 1990 chez Mimomyia lacustris, un moustique de la famille des Culicidae (numéro d'accession GenBank DQ318019) (figure 1).

\section{Détection de Babesia sp.}

Les extraits d'ADN émanant des plasmas des bovins ont été analysés par PCR spécifique du genre Babesia. Ainsi, un fragment de $452 \mathrm{pb}$ du gène ARNr $18 \mathrm{~S}$ a été amplifié chez 5 zébus, soit un taux d'infection global de 4\% (5/125). Les animaux infectés étaient tous des zébus de race Goudali (G38, G40, G96, G98 et G100), correspondant à un taux d'infection de $4,46 \%(5 / 112)$ pour la race.

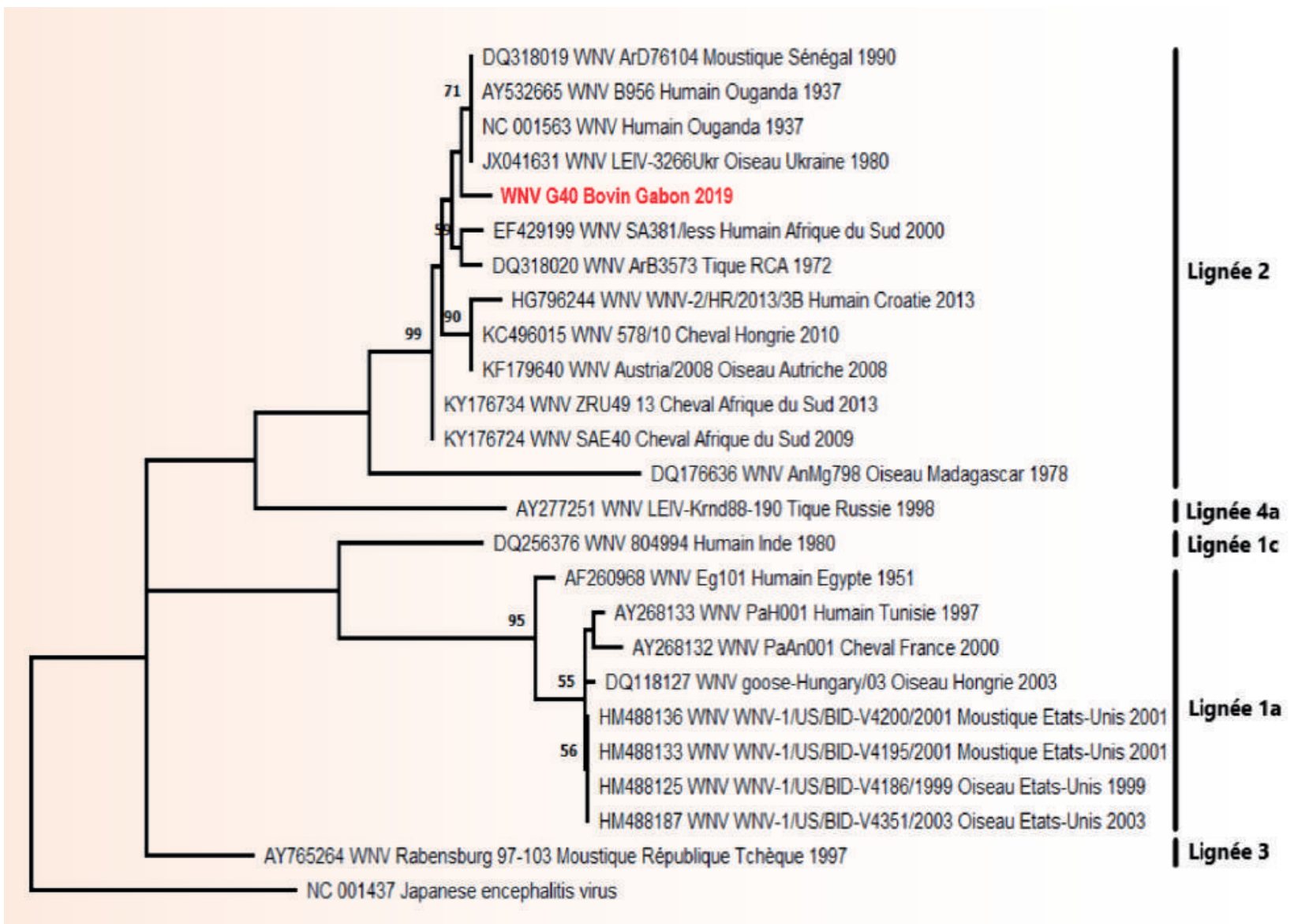

Figure 1: Arbre phylogénétique basé sur le gène partiel (210 pb) de la protéine non structurale 5 utilisé pour l'identification de l'infection par le virus du Nil occidental. Le pourcentage d'arbres dans lesquels les taxons associés se regroupent est indiqué à côté des branches (les valeurs de bootstraps inférieures à 55 n'ont pas été affichées). L'arbre est dessiné à l'échelle, la longueur des branches étant mesurée en nombre de substitutions par site. La séquence de la souche gabonaise avait une taille <200 pb et n'a donc pas pu être déposée dans GenBank. 


\section{DISCUSSION}

Cette étude avait pour objectif de rechercher et d'identifier des agents pathogènes chez les bovins importés sur pied pour la consommation de viande et abattus au niveau de l'abattoir national d'Owendo. En effet, l'abattoir constitue un excellent site de veille sanitaire selon Vanelle (2018) et permettrait de contribuer à la quasi-éradication des grandes maladies animales transmissibles à l'homme (Domenech, 2013).

Les analyses effectuées ont permis de mettre en évidence le virus du Nil occidental chez un zébu de race Goudali, corroborant le rôle de réservoirs de ce virus que l'espèce bovine pourrait jouer, bien que Gould \& Fikrig (2004) aient rapporté des signes cliniques de l'infection par le virus chez les bovins. Des antigènes spécifiques du virus avaient été retrouvés dans les tissus de ces derniers, suggérant leur rôle de potentiels réservoirs (AFSSA, 2004 ; Zientara et al. 2001). Par ailleurs, le virus du Nil occidental est associé à une maladie fébrile, une méningo-encéphalite et la mort chez l'homme et le cheval (Murray et al. 2011 ; Pauli et al. 2013). Aux Étas-Unis, plus précisément au Texas, le taux de mortalité de cette maladie chez l'homme oscille autour de $13 \%$ mais dans les cas de la forme neuro-invasive associés à cette pathologie, ce taux atteint la valeur de $92 \%$ (Philipot et al. 2019). Au Gabon, un cas de méningo-encéphalite mortelle dû au virus du Nil occidental a été rapporté. Le virus avait été diagnostiqué par biologie moléculaire sans toutefois qu'il n'ait été caractérisé génétiquement (Mandji Lawson et al. 2009). Dans la présente étude, la souche du virus identifiée chez le bovin appartenait à la lignée 2. Il s'agit donc là, de la première caractérisation moléculaire du virus dans ce pays. D'un point de vue phylogénétique, le virus du Nil occidental se subdivise en 6 lignées (1 à 6) (Sule et al. 2018). Deux lignées principales, les lignées 1 et 2 , identifiées en Afrique après le premier isolement en Ouganda. La lignée 1 est composée de trois sous-lignées a, b et c. La lignée 2 du virus comprend des souches isolées en Afrique sub-saharienne (Petersen \& Roehrig, 2001). Selon Zeller \& Schuffenecker (2004) et Hernández-Triana et al. (2014), les lignées 1 et 2 sont les plus importantes du point de vue de la santé publique, provoquant des épidémies en Amérique du Nord et en Europe. Elles seraient probablement sous-déclarées en Afrique (Sule et al. 2018). Par ailleurs, une grande enquête sérologique réalisée par Pourrut et al. (2010) sur 2320 personnes parmi des populations rurales du Gabon, avait mis en évidence une prévalence globale élevée (27,2\%) d'immunoglobulines $G$ ( $\operatorname{IgG}$ ) spécifiques du virus du Nil occidental, suggérant que ce virus serait largement répandu au Gabon et que les populations y seraient exposées de façon continue. Nos résultats obtenus chez les bovins suggèrent que ces derniers pourraient être des espèces réservoirs du virus, autrement dit, ces animaux pourraient favoriser la survie du virus dans la nature en l'absence de maladie manifeste (Ozkul et al. 2006). En effet, bien que peu d'études aient rapporté la présence de l'ARN du virus du Nil occidental chez les bovins (Steyn et al. 2019), nombreuses sont celles qui ont révélé la présence d'anticorps IgG dirigés contre ce virus chez les bovins domestiques aussi bien en Turquie (Ozkul et al. 2006), en Egypte (Selim \& Abdelhady, 2020) qu'en Ethiopie (Endale et al. 2021). La présence du virus du Nil occidental chez un bovin de cette étude soulève un risque de transmission à l'homme. Ces résultats mettent ainsi en lumière la nécessité de renforcer la surveillance des bovins et d'autres espèces animales, chez lesquelles le virus pourrait circuler à bas bruit. Les bovins pourraient ainsi servir d'animaux sentinelles pour la surveillance du virus du Nil occidental. Enfin, cette surveillance pourrait être réalisée chez les oiseaux domestiques et sauvages (principaux réservoirs), mais également chez les moutons (Rimoldi et al. 2017), les chats (Egberink et al. 2015) et les rongeurs (Root, 2013), chez lesquelles le virus a été responsable de nombreux cas de mortalité et morbidité.

Bien que le virus du Nil occidental soit principalement transmis par les moustiques du genre Culex (principalement C. univittatus et C. pipiens) (Sardelis, 2001 ; Kramer et al. 2007 ; Kilpatrick, 2008 ; Hamer, 2009), des preuves de transmission par les tiques ont également été documentées (Komar, 2003 ; Lawrie, 2004), indiquant le rôle potentiel des tiques dans la transmission du virus, comme source d'infection. Au Kenya, le virus avait été isolé de Rhipicephalus pulchellus, espèce de tique la plus abondante chez le bétail des zones pastorales du pays. De plus, des études de compétence vectorielle, réalisées sur Hyalomma marginatum au Portugal, avaient démontré le rôle de ces tiques dans la transmission naturelle du virus (Formosinho \& Santos-Silva, 2006). Dans leur étude réalisée à l'abattoir national d'Owendo, Moubamba Mbina et al. (2020) avait rapporté que Hyalomma truncatum et Hyalomma impeltatum étaient deux des trois espèces de tiques anthropophiles introduites du Cameroun vers le Gabon à partir des zébus. Des études virologiques devraient être menées chez les tiques pour déterminer leur rôle dans la transmission de ce virus.

Les tiques transmettent par ailleurs des parasites hémoprotozoaires des vertébrés du genre Babesia, qui ont un impact majeur sur la production animale, principalement chez les bovins et les petits ruminants, dans les zones tropicales et subtropicales (Mehlhorn \& Schein, 1984). Cette étude a en effet révélé l'infection des zébus par les hémoparasites Babesia sp., corroborant les résultats de Koundi en 2017 (données non publiées) qui avait trouvé $55 \%$ de tiques prélevées sur des bovins à l'abattoir national d'Owendo, infectées par ce parasite. Au Burkina Faso, Badolo (2014) avait révélé chez les bovins une prévalence d'infection par Babesia de 31\%, largement supérieure à celle obtenue dans la présente étude, soit 4\%. Ce faible taux d'infection pourrait résulter, d'une part, de la faible sensibilité de la PCR générique utilisée, et d'autre part, de la période parasitémique relativement courte chez la plupart des animaux, étant donné que la recherche de Babesia sp. a été effectuée dans le sang.

Certains agents pathogènes n'ont pas pu être détectés dans cette étude soit à cause de leur absence effective chez les bovins, soit du fait de la faible spécificité et/ou de la faible sensibilité des amorces utilisées. Dans le cas de la recherche bactérienne, la culture aurait pu être utilisée en complément de la PCR. En effet, dans leurs études, Alonso et al. (2012), Momtaz \& Jamshidi (2013) et Bennani et al. (2016) avaient mis en évidence les salmonelles et des campylobacter en ayant réalisé la culture avant d'effectuer des tests de PCR. Donc, bien que les amorces dégénérées confèrent un large spectre de détection d'agents pathogènes, elles sont également limitées par une faible sensibilité et spécificité vis à vis des agents infectieux recherchés, cause probable des 
amplifications non spécifiques obtenues pour la PCR panflavivirus.

En somme, la surveillance initiée au niveau de l'ANO devrait être renforcée, pérennisée et être étendue au niveau des aires d'abattage connues du Gabon. Aussi, il serait important de mettre en place une surveillance directement au niveau des frontières avec observation de la période de quarantaine exigée. En France, le dispositif pilote nommé Nergal-Abattoir a été mis en place dans 10 abattoirs ayant pour but la collecte en temps réel, au cours du processus d'abattage, des informations relatives à l'inspection en abattoir (Pujol-Dupuy, 2014).

\section{CONCLUSION}

La détection du virus du Nil occidental chez l'homme et les animaux au Gabon, révèle la nécessité de mettre en place une surveillance, non seulement au niveau des abattoirs et des aires d'abattages, des frontières mais également à un niveau plus global intégrant une surveillance entomologique, aviaire et une surveillance du syndrome neurologique. Des études complémentaires devraient être réalisées pour mieux caractériser les agents pathogènes hébergés par les bovins.

\section{REMERCIEMENTS}

Les auteurs remercient la Direction de l'AGASA et l'ensemble du personnel de l'abattoir de l'ANO impliqué dans la collecte des échantillons. Nos remerciements vont également à l'endroit des Docteurs Larson Boundenga et Illich Mombo pour leur aide dans l'analyse des résultats. Nous remercions également l'Unité de bactériologie du Centre Interdisciplinaire de Recherches Médicales de Franceville (CIRMF) et particulièrement le Dr Richard Onanga et Arsène Mabika Mabika pour leur soutien matériel et technique. Le CIRMF est soutenu par le Gouvernement du Gabon, Total-Fina-Elf Gabon et le Ministère de la Coopération Français

\section{BIBLIOGRAPHIE}

- AFSSA. Rapport sur la surveillance de l'infection à virus West Nile en France. 2004. Disponible à : https://www. anses.fr/fr/system/files/SANT. Ra-WestNile.pdf (consulté le 15.05.2021).

- Alonso MZ, Lucchesi PMA, Rodríguez EM, Parma AE, Padola NL. Enteropathogenic (EPEC) and Shigatoxigenic Escherichia coli (STEC) in broiler chickens and derived products at different retail stores. Food Control. 2012; 23: 351-355.

- Altschul SF, Lipman DJ. Protein database searches for multiple alignments. Proceedings of the National Academy of Sciences of the United States of America. 1990;87(14): 5509-5513.

- Ayelet G, Mana M, Esayas G, Berhe GE, Tesfaye R, Mesfin S et al. Genetic Characterization of Foot-and-Mouth Disease Viruses, Ethiopia, 1981-2007. Emerg Infect Dis. 2009;15(9): 1409-1417.

- Badolo H. Contribution à l'étude épidémiologique des anaplasmoses et des babésioses suite à l'introduction récente de la tique Rhipicephalus (Boophilus) microplus (Canestrini, 1888) dans le Sud-Ouest du Burkina Faso. Mémoire de fin de cycle. Institut du Développement Rural (IDR). Université Polytechnique de Bobo Dioulasso (UPB). 62p. 2014. Disponible à : http://www.beep.
ird.fr/collect/upb/index/assoc/IDR2014-BAD-CON/IDR-2014-BAD-CON. pdf (consulté le 15.12.2020).

- Bennani L, Berrada S, Salame B, Aabouch M, El Ouali Lalami A. L'évaluation de la qualité hygiénique des viandes et de certains produits carnés prélevés de la ville de Fès, Maroc. International Journal of Innovation and Applied Studies. 2016; 15(3): 547-554.

- Casati S. Etude sur la diversité génétique des tiques Rhipicephalus sanguineus et Ixodes ricinus, et des agents pathogènes Rickettsia sp, Coxiella sp, Borrelia burgdorferi sensu lato, Babesia sp. et le virus de l'encéphalite à tiques en Suisse. Thèse de doctorat, Université de Neuchâtel. 152 pages. 2005. Disponible à http://doc.rero.ch/client/fr/get\&th eme=gray\&file=1\&url=http: $/ /$ doc.r ero.ch/record/5470/export/xm (consulté le 20.01.2021).

- Cook S, Bennett SN, Holmes EC, De Chesse R, Moureau G, de Lamballerie X. Isolation of a new strain of the flavivirus cell fusing agent virus in a natural mosquito population from Puerto Rico. J Gen Virol. 2006;87: 735-748.

- Crochu S, Cook S, Attoui H, Charrel $\mathrm{RN}$, De Chesse R, Belhouchet $\mathrm{M}$ et al. Sequences of flavivirus-related RNA viruses persist in DNA form integrated in the genome of Aedes spp. mosquitoes. J Gen Virol. 2004;85: 1971-1980.

- De Souza Luna LK, Heiser V, Regamey N, Panning M, Drexler JF, Mulangu S et al. Generic Detection of Coronaviruses and Differentiation at the Prototype Strain Level by Reverse Transcription-PCR and Nonfluorescent Low-Density Microarray. Journal of Clinical Microbiology. 2007; 45(3): 1049-1052.

- Domenech J. Les grandes maladies animales épizootiques et transfrontalières : les principes de la lutte dans les pays du Sud. Bull Acad Vét France. 2013;166(4): 328-337.

- Drosten C, Göttig S, Schilling S, Asper M, Panning M, Schmitz $\mathrm{H}$ et al. Rapid Detection and Quantification of RNA of Ebola and Marburg Viruses, Lassa Virus, Crimean Congo Hemorrhagic Fever Virus, Rift Valley Fever Virus, Dengue Virus, and Yellow Fever Virus by Real-Time Reverse Transcription-PCR. J Clin Microbiol. 2002;40(7): 2323-2330.

- Egberink H, Addie D.D, Boucraut-Baralon C, Frymus T, Gruffydd-Jones T, Hartmann K, Horzinek M.C, Hosie M.J, Marsilio F, Lloret A. West Nile 
virus infection in cats: $A B C D$ guidelines on prevention and management. J. Feline Med. Surg. 2015;17: 617-619. - Endale A, Michlmayr D, Erku Abegaz W, Geda B, Asebe G, Medhin G, Larrick JW, Legesse M. Sero-prevalence of West Nile virus and Rift Valley fever virus infections among cattle under extensive production system in South Omo area, southern Ethiopia. Trop Anim Health Prod. 2021;53: 92.

-Esemu SN, Ndip RN, Ndip LM. Detection of Ehrlichia ruminantium infection in cattle in Cameroon. BMC Res Notes. 2018;11: 388.

- Formosinho P, Santos-Silva M: Experimental infection of Hyalomma marginatum ticks with West Nile virus. Acta Virol (Praha). 2006;50(3): 175.

- Gould LH, Fikrig E. West Nile virus: a growing concern? J Clin Invest. 2004;113: 1102-7.

- Grace D, Gilbert J, Randolph T, Kang'ethe E. The multiple burdens of zoonotic disease and an ecohealth approach to their assessment. Trop Anim Health Prod. 2012;44(S1): 67-73.

- Grace D, Songe M, Knight-Jones T. Impact des maladies négligées sur la productivité animale et la santé publique en Afrique. Afrique-Commission Régionale OIE. Organisation Mondiale de la Santé Animale. 33 pages. 2015. Disponible à : https://www.oie.int/fr/ document/2015_afr1_grace_f/ (consulté le 26.08.2021).

- Hamer GL. Host selection by Culex pipiens mosquitoes and West Nile virus amplification. Am J Trop Med Hyg. 2009;80(2): 268 .

- Hernández-Triana LM, Jeffries CL, Mansfield KL, Carnell G, Fooks AR, Johnson N. Emergence of West Nile virus lineage 2 in Europe: a review on the introduction and spread of a mosquito-borne disease. Front Public Health. 2014;2:271.

- Kilpatrick AM. Temperature, viral genetics, and the transmission of West Nile virus by Culex pipiens mosquitoes. PLoS Pathog. 2008;4(6): e1000092.

- Komar N. Experimental infection of North American birds with the New York 1999 strain of West Nile virus. Emerg Infect Dis. 2003;9(3): 311.

- Kong RY, Lee SK, Law TW, Law SH, Wu RS. Rapid detection of six types of bacterial pathogens in marine waters by multiplex PCR. Water Res. 2002;36: 2802-12.

- Kramer LD, Li J, Shi PY. West Nile virus. Lancet Neur. 2007; 6(2): 171-181.

- Kumar S, Stecher G, Li M, Knyaz C, Tamura K. MEGA X: Molecular Evolutionary Genetics Analysis across computing platforms. Molecular Biology and Evolution. 2018;35: 1547-1549.

- Lancelot R, Zundel E, Ducrot C. Spécificités de la santé animale en régions chaudes : le cas des maladies infectieuses majeures en Afrique. INRA Productions Animales. 2011;24(1): 65-76.

- Lawrie CH. Ixodid and argasid tick species and West Nile virus. Emerg Infect Dis. 2004; 10(4): 653.

- Li Y, Cao B, Liu B, Liu D, Gao Q, Peng $\mathrm{X}$ et al. Molecular detection of all 34 distinct O-antigen forms of Shigella. J Med Microbiol. 2009;58: 69-81.

- MAEDRCDHM. Rapport national sur l'état des ressources génétiques animales du Gabon. 2003. Disponible à : http://www.fao.org/3/a1250e/ annexes/CountryReports/Gabon.pdf (consulté le 15.12.2020).

- MAEPG. Politique Nationale de Sécurité Alimentaire et Nutritionnelle (PNSAN) 2017-2025. Gabon. 2017. Disponible à : http://scalingupnutrition.org/ wp-content/ uploads/2017/05/Version-finale-dela-PNSAN-Gabon-Mai-2017.pdf (consulté le 15.12.2020).

- Mandji Lawson JM, Mounguengui D, Ondounda M, Nguema Edzang B, Vandji J, Tchoua R. A case of meningo-encephalitis due to West Nile virus in Libreville, Gabon. Med Trop. 2009; 69: 501-2.

- McDaniel CJ, Cardwell DM, Moeller Jr RB, Gray GC. Humans and Cattle : A Review of Bovine Zoonoses. Vector-Borne and Zoonotic Diseases. 2014;14(1): 1-19.

- Mehlhorn H, Schein E. The piroplasms: life cycle and sexual stages. Adv. Parasitol. 1984;23: 37-103.

- Momtaz H, Jamshidi A. Shiga toxin-producing Escherichia coli isolated from chicken meat in Iran: serogroups, virulence factors, and antimicrobial resistance properties. Poult Sci. 2013;92(5): 1305-13.

- Moubamba Mbina D, Ntountoume Ndong A, Maganga GD. Amblyomma variegatum Hyalomma truncatum and
Hyalomma impeltatum Anthropophilic Ticks Introduced to Gabon by the Fulbe Zebus from Cameroon: their Predilection Sites and Ability to Live in Gabon. Archives of Veterinary Science and Medicine. 2020;3: 11-20. - Murray KO, Walker C, Gould E. The virology, epidemiology, and clinical impact of West Nile virus: a decade of advancements in research since its introduction into the Western Hemisphere. Epidemiol Infect. 2011;139: 807-17.

- Ozkul A, Yildirim Y, Pinar D, Akcali A, Yilmaz V, Colak D. Serological evidence of West Nile Virus (WNV) in mammalian species in Turkey. Epidemiol Infect. 2006;134: 826-829.

- Pauli G, Bauerfeind U, Blümel J, Burger R, Drosten C, Gröner A, et al. West Nile virus. Transfus Med Hemother. 2013;40: 265-84.

- Petersen LR, Roehrig JT. West Nile virus: a reemerging global pathogen. Rev Biomed. 2001; 12: 208-216.

- Philpott DCE, Nolan MS, Evert N, Mayes B, Hesalroad D, Fonken E et al. Acute and Delayed Deaths after West Nile Virus Infection, Texas, USA, 2002-2012. Emerg Infect Dis. 2019;25(2): 256-264.

- Pourrut X, Nkoghé D, Paweska J, Leroy E. First serological evidence of West Nile virus in human rural populations of Gabon. Virol J. 2010; 7: 132.

- Pujol-Dupuy C. Analyse et modélisation des données d'inspection en abattoir dans l'objectif de contribuer à la surveillance épidémiologique de la population bovine. Thèse de doctorat, Université Claude Bernard de Lyon 1. 250 Pages. 2014. Disponible à : https://www.theses.fr/081514166 (consulté le 20.01.2021).

- Rimoldi G, Mete A, Adaska J, Anderson M, Symmes K, Diab S. West Nile Virus Infection in Sheep. Vet. Pathol. 2017;54: 155-158.

- Rodas C, Iniguez V, Qadri F, Wiklund G, Svennerholm A-M, Sjöling A. Development of multiplex PCR assays for detection of enterotoxigenic Escherichia coli colonization factors and toxins. J Clin Microbiol. 2011;47: 1218-20.

- Roger F. Lutte contre les zoonoses en Afrique et en Asie. L'apport de la recherche à "Une seule Santé". Perspec- 
tive. 2012; (18): 1-4.

- Root J.J. West Nile virus associations in wild mammals: A synthesis. Arch. Virol. 2013;158: 735-752.

- Roux V, Fournier PE, Raoult D. Differentiation of spotted fever group rickettsiae by sequencing and analysis of restriction fragment length polymorphism of PCR-amplified DNA of the gene encoding the protein rOmpA. J Clin Microbiol. 1996;34(9): 2058-2065.

- Saiki RK, Scharf S, Faloona F, Mullis KB, Horn GT, Arnheim N. Enzymatic amplification of globin genomic sequences and restriction site analysis for diagnosis of sickle cell anemia. Science. 1985;230: 1350-1354.

- Sánchez-Seco MP, Echevarría JM, Hernández L, Estévez D, Navarro-Marí JM, Tenorio A. Detection and Identification of Toscana and Other Phleboviruses by RT-Nested-PCR Assays With Degenerated Primers. Journal of Medical Virology. 2003;71: 140-149.

- Sardelis MR. Vector competence of selected North American Culex and Coquillettidia mosquitoes for West Nile virus. Emerg Infect Dis. 2001;7(6): 1018. Selim A \& Abdelhady A. The first detection of anti-West Nile virus antibody in domestic ruminants in Egypt. Trop
Anim Health Prod. 2020;52: 3147-3151. - Sjöling Å, Sadeghipoorjahromi L, Novak D, Tobias J. Detection of major diarrheagenic bacterial pathogens by multiplex PCR panels. Microbiol Res. 2015;172: 34-40.

-Sjöling A, Wiklund G, Savarino SJ, Cohen DI, Svennerholm AM. Comparative analyses of phenotypic and genotypic methods for detection of enterotoxigenic Escherichia coli toxins and colonization factors. J Clin Microbiol. 2007;45: 3295-301.

-Steyn J, Botha E, Stivaktas VI, Buss P, Beechler BR, Myburgh JG, Steyl J, Williams J, Venter M. West Nile Virus in Wildlife and Nonequine Domestic Animals, South Africa, 2010-2018. Emerg Infect Dis. 2019;25(12): 2290-2294

- Sule WF, Oluwayelu DO, Hernández-Triana LM, Fooks AR, Venter M, Johnson N. Epidemiology and ecology of West Nile virus in sub-Saharan Africa. Parasites \& Vectors. 2018;11:414

- Tamura K, Nei M. Estimation of the number of nucleotide substitutions in the control region of mitochondrial DNA in humans and chimpanzees. Molecular Biology and Evolution. 1993;10: 512-526.
- Tobias J, Vutukuru SR. Simple and rapid multiplex PCR for identification of the main human diarrheagenic Escherichia coli. Microbiol Res. 2012;167: 564-70.

-Tong S, Chern SW, Li Pallansch MA, Anderson LJ. Sensitive and broadly reactive reverse transcription-PCR assays to detect novel paramyxoviruses. J Clin Microbiol. 2008;46: 2652-2658.

-Vanelle AM. De la place de l'inspection vétérinaire en abattoir en santé publique vétérinaire. Evolutions et perspectives. Bull Acad Vét France. 2018;171(2): 106-116.

- Vidal P, Vidal M, Lagos R, Levine M, Prado V. Multiplex PCR for diagnosis of enteric infections associated with diarrheagenic Escherichia coli. J Clin Microbiol. 2004:42: 1787-9.

- Zeller HG, Schuffenecker I. West Nile virus: an overview of its spread in Europe and the Mediterranean basin in contrast to its spread in the Americas. Eur J Clin Microbiol Infect Dis. 2004;23: 147-56.

-Zientara S, Murgue B, Zeller H, Dufour B, Murri S, Labie J et al. Maladie à virus "West Nile" en France. Epidémiol. et santé anim. 2001;39: 113-120. 